\title{
Rheumatoid arthritis: a joint venture
}

\author{
EL Potgieter \\ Synexus Clinical Research Ltd, South Africa \\ Corresponding author, email: elsjepot@gmail.com
}

Rheumatoid arthritis (RA) is a chronic auto-immune inflammatory disorder, usually affecting the joints. Its prevalence is estimated at $0.3-1 \%$ in industrialised countries and areas of urban living. ${ }^{1-3}$ RA leads to functional disability, significant pain and joint destruction, and subsequent loss of income: in developed countries half of people diagnosed with RA are unable to sustain full-time employment ten years after diagnosis. ${ }^{4}$ It also carries substantial cardiovascular risk if inadequately treated. RA is possibly the largest cause of treatable disability in the Western World. ${ }^{5}$ The exact prevalence of RA in South Africa is currently not known, but its significant impact is compounded by frequent late diagnoses and a scarcity of treating specialists. ${ }^{6-8}$

The most important aim in treating RA is to prevent structural joint damage whilst improving symptoms and function. This is primarily achieved with pharmacological therapy - specifically disease-modifying antirheumatic drugs (DMARDs) - with glucocorticosteroids and analgesia as symptomatic treatment agents. ${ }^{9,10}$

Ideally, patients presenting with symptoms suggestive of RA should be cared for by a rheumatologist, or at least a specialist physician, especially in complex cases. ${ }^{9}$ This is not possible in the South African context, where large parts of the population have limited access to specialist healthcare. As joint damage begins within 3-6 months after disease onset, it is imperative that treatment is initiated as soon as possible. The burden of treating these patients can then fall to the general practitioner to initiate and monitor treatment in order to prevent joint damage and reducing later disability. ${ }^{4,11,12}$

Only $56 \%$ of patients will respond adequately to a six-month trial of methotrexate (MTX) and/or other conventional synthetic disease-modifying antirheumatic drugs (csDMARDs). ${ }^{13} \mathrm{~A}$ trial of three to six months is reasonable before treatment is adjusted according to the degree of improvement. This improvement should be measured by using a standard scoring system such as the disease activity 28 joint score (DAS28), with the aim of reaching sustained remission or low disease activity (LDA). ${ }^{9,10}$

Since MTX was first used for the treatment of RA in $1951,{ }^{14}$ much has been learned about the disease itself and its treatment. The current available csDMARDs include MTX, chloroquine, sulfasalazine (SSZ) and leflunomide, used either as monotherapy or in combination. The South African guidelines recommend initiating treatment with a synthetic DMARD: in the absence of contraindications, MTX is generally accepted as a good first choice. A second cSDMARD can be added in the presence of poor prognostic factors including seropositivity, radiographic erosions within the first two years, extra-articular complications or functional disability. ${ }^{10,15-17}$

The following should be kept in mind when prescribing pharmacological therapy for RA:

\section{Conventional synthetic DMARDs}

\section{Methotrexate}

This is the most widely used drug in the treatment of RA. It is the recommended first-line therapy, either as monotherapy or as combination therapy, as it has a faster onset of action, comparable or greater efficacy and better long-term tolerance compared to any of the other csDMARDs as monotherapy. The dose is 7.5-25 mg once a week, orally or subcutaneously, and it is co-prescribed with $5 \mathrm{mg}$ of folic acid per week.

A number of patients experience side-effects to some degree, usually mild nausea, headache, fatigue or feeling generally unwell for a day or two after each weekly dose, although it may be more severe and some may also develop mouth ulcers. Taking it in the evening may help and an anti-emetic may be used. The dose may be split over a 24 hour period, but never over a week - more frequent dosing increases the risk for long-term serious adverse effects.

Although rare, more serious and potentially life-threatening adverse effects may occur, e.g. pneumonitis, bone marrow depression and drug-induced hepatitis/hepatic fibrosis. Regular monitoring to recognise these timeously is therefore imperative. A weekly subcutaneous dose may be considered as this route is less inclined to cause nausea and is more effective due to better absorption. MTX is teratogenic and contraception requirements should be carefully evaluated prior to initiation of treatment. It is advised that MTX be stopped three months prior to conception in both men and women, i.e. when contraception is stopped.

MTX can be co-prescribed with chloroquine, SSZ or the biological DMARDs. Pregnancy and breastfeeding, alcoholism, liver disorders, bone marrow suppression, interstitial lung disease, all, however, preclude the use of MTX.10,18,19 
Table I: Monitoring requirements for csDMARDs

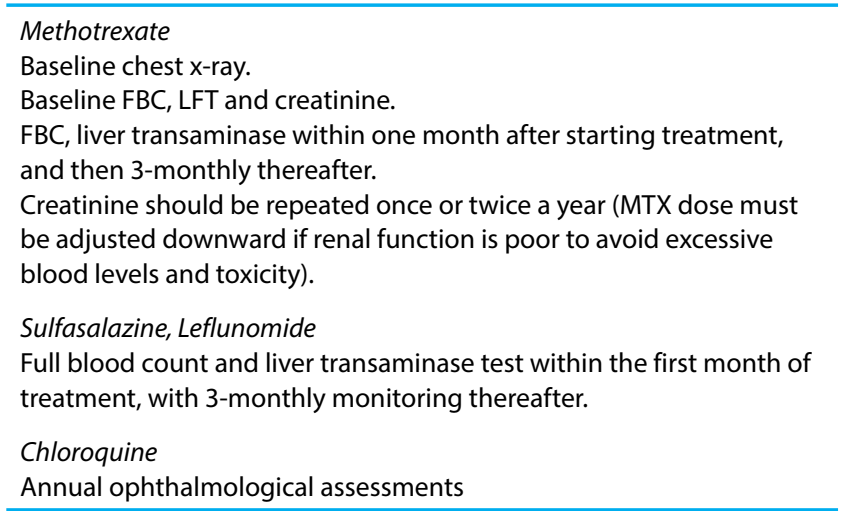

\section{Sulfasalazine}

SSZ as monotherapy gives another option in patients who cannot tolerate MTX, or for whom a contraindication exists. It can also form part of combination therapy. The usual prescribed dose is 1-2 $\mathrm{g} /$ day, orally, although $3 \mathrm{~g} / \mathrm{d}$ may be used. Common sideeffects include $\mathrm{Gl}$ intolerance, skin rash, elevated liver enzymes and myelosuppression.

SSZ should be avoided in patients with hypersensitivity to sulfasalazine, its metabolite, sulfonamides, salicylates, or any component of the formulation. It is also contraindicated in patients with renal damage or urinary obstruction, as it is excreted in the urine and may cause crystalluria and nephrolithiasis. SSZ can precipitate an acute porphyric attack and should be avoided in patients with porphyria. ${ }^{10,20}$

\section{Leflunomide}

Leflunomide may be used as monotherapy or in combination with MTX in patients with RA. The dose is $20 \mathrm{mg} /$ day orally, or every alternate day. Common side-effects include nausea, vomiting, abdominal pain, diarrhoea, alopecia, elevated liver enzymes and skin rash. A wash-out with cholestyramine is advised if patients suffer leflunomide-induced hepatotoxicity. It should be kept in mind that this drug is teratogenic in both male and female patients. Leflunomide should therefore be suspended two years before a possible pregnancy. ${ }^{10}$

\section{Chloroquine}

Chloroquine may be used as monotherapy in patients with contraindications to MTX and mild to moderate disease. It may also form part of combination therapy. One of the big advantages of chloroquine is that it is considered safe during both pregnancy and breastfeeding, unlike MTX or leflunomide. The usual dose is $200 \mathrm{mg} /$ day, with many patients doing well on $200 \mathrm{mg}$ three to five days a week in an effort to avoid side-effects.

These side-effects include Gl intolerance, skin hyperpigmentation, headache and dizziness. Less commonly, but more concerning, a retinopathy/maculopathy (irreversible if not recognised very early) can occur - which is the main reason why daily dosing is often not recommended. A patient's body mass must also be taken into account.
Contraindications include a known hypersensitivity to chloroquine, concurrent tamoxifen use (as it also increases the risk of a retinopathy, can cause QT-prolongation) or a pre-existing retinopathy/maculopathy. ${ }^{10,21}$

\section{Adjuncts to DMARDs}

\section{Glucocorticoids}

Short-term glucocorticoids can assist in reducing RA symptoms and should be considered when initiating or changing DMARDS. They are not appropriate as monotherapy and should be tapered as quickly as clinically feasible. Low dose oral prednisone (10 mg/day or less) or long-acting intramuscular methylprednisone may be used for up to six months in early RA, but should be withdrawn once the disease is controlled. Sideeffects limit their long term use..$^{9,10}$

\section{Analgesia}

Analgesia should be prescribed to be taken as and when needed for symptomatic relief, while considering the relevant drug's potential toxicities and the patient's risk profile. In particular, it should be kept in mind that many RA patients have an increased risk for a nonsteroidal anti-inflammatory drug (NSAID)-induced gastrointestinal tract event (chronicity of use, glucocorticosteroid use) as well as an increased cardiovascular risk because of RA itself. These risks should be carefully monitored when NSAIDs are prescribed, while the addition of a proton-pump inhibitor (PPI) or using a cyclo-oxygenase (COX)-2 selective agent should also be considered if the decision is taken to proceed with NSAIDs. ${ }^{22,23}$

\section{Biological DMARDs}

When remission/LDA cannot be achieved with the synthetic drugs alone, biological DMARDs offer additional treatment options. ${ }^{24-26}$ Escalation from conventional to a biological DMARD is recommended for patients with high disease activity (SDAI 11-26) with poor prognostic factors including seropositivity, radiographic erosions withing the first two years, extra-articular complications or functional disability. ${ }^{10}$ When biological DMARD therapy is instituted, it is effective in approximately two-thirds of patients who have failed to respond to traditional csDMARDs. Of note is that biological DMARDs are usually co-prescribed with MTX to improve efficacy and to reduce antichimeric antibody production. $4,10,27,28$

The seven biological DMARDs licensed in South Africa for the treatment of rheumatoid arthritis include therapies that target TNF-a (infliximab, adalimumab, etanercept and golimumab, with biosimilars available for the first two) and the non-anti-TNF drugs (abatacept, tocilizumab and rituximab), the latter preferable in groups where there is a high risk for tuberculosis (TB). 15,10,26 The reactivation of TB is a real risk in the South African setting where there is a high prevalence of TB and HIV. ${ }^{10,29}$ Other risks associated with biological DMARDs include infection in general as well as reactivation of hepatitis, worsening of heart failure, and development of lymphoma or autoimmunity. In the correctly selected patient, most side-effects and risks can be managed, 
with the potential benefit outweighing these concerns. However, treatment with bDMARDs may only be initiated by a rheumatologist where strict guidelines and recommendations are followed to determine which patients would benefit the most, and to manage the risks inherent to biological therapy. This remains out of reach to most South African RA sufferers. $4,12,15,25,30,31$

\section{Targeted synthetic DMARDs}

A new class of drugs, called Janus kinase inhibitors (JAKi) are orally administered small molecule DMARDs available in select countries for the treatment of RA. These, however, are not yet available in South Africa.

\section{Conclusion}

There has been great progress in the treatment of RA. Currently, there are various options that are used either alone or in combination depending on disease response and severity. Conventional synthetic, targeted synthetic and biological DMARDs are useful therapeutic choices that allow a significant number of patients to achieve low disease activity and remission. Glucocorticoids and NSAIDs are also useful as adjunctive bridging treatments and analgesics. Early diagnosis, however, is critical in order to maximise these therapeutic opportunities.

\section{Conflict of interest}

The author declares no conflict of interest.

\section{Funding source}

None.

\section{ORCID}

\section{EL Potgieter (iD) https://orcid.org/0000-0002-7865-2549}

\section{References}

1. Kalla A, Tikly M. Rheumatoid arthritis in the developing world. Best Pract Res Clin Rheumatol. 2003;17(5):863-75. https://doi.org/10.1016/S1521-6942(03)00047-0.

2. Woolf $A D$, Pfleger B. Burden of major musculoskeletal conditions. Bull World Health Organ. 2003;81:646-56.

3. Uhlig T, Moe RH, Kvien TK. The burden of disease in rheumatoid arthritis. Pharmacoeconomics. 2014;32(9):841-51. https://doi.org/10.1007/ s40273-014-0174-6.

4. Horton S, Buch MH, Emery P. Efficacy, tolerability and safety of biologic therapy in rheumatoid disease: Patient considerations. Drug Healthc Patient Saf. 2010;2(1):101-19. https://doi.org/10.2147/DHPS.S6317.

5. Kvien TK. Epidemiology and burden of illness of rheumatoid arthritis. Pharmacoeconomics. 2004;22(S1):1-12. https://doi. org/10.2165/00019053-200422001-00002.

6. Ally MM, Meyer PW, Anderson R. Early rheumatoid arthritis: focus on RA in the developing world. South African Fam Pract. 2016;6190(July):1-3. Available from: http://www.tandfonline.com/doi/full/10.1080/20786190.2016.1177988.

7. Hodkinson B, Musenge $E$, Ally $M$, et al. Functional disability and healthrelated quality of life in South Africans with early rheumatoid arthritis. Scand J Rheumatol. 2012 Oct 18;41(5):366-74. https://doi.org/10.3109/03009742.2012. 676065.

8. Mody GM, Cardiel MH. Challenges in the management of rheumatoid arthritis in developing countries. Best Pract Res Clin Rheumatol. 2008;22(4):621-41. https:// doi.org/10.1016/j.berh.2008.04.003.

9. Smolen JS, Landewe RBM, Bijlsma JWJ, et al. EULAR recommendations for the management of rheumatoid arthritis with synthetic and biological diseasemodifying antirheumatic drugs: 2019 update. Ann Rheum Dis. 2020;79(6):68599. https://doi.org/10.1136/annrheumdis-2019-216655.

10. Hodkinson B, Van Duuren E, Pettipher C, Kalla A; South African Rheumatism and Arthritis Association. South African recommendations for the management of rheumatoid arthritis: an algorithm for the standard of care in 2013. South African Med J. 2013;103(8):577-85. https://doi.org/10.7196/SAMJ.7047.
11. Anyfanti $P$, Triantafyllou $A$, Panagopoulos $P$, et al. Predictors of impaired quality of life in patients with rheumatic diseases. Clin Rheumatol. 2016;35(7):1705-11. https://doi.org/10.1007/s10067-015-3155-z.

12. Rantalaiho V, Korpela M, Laasonen L, et al. Early combination disease-modifying antirheumatic drug therapy and tight disease control improve long-term radiologic outcome in patients with early rheumatoid arthritis: the 11-year results of the Finnish Rheumatoid Arthritis Combination Therapy trial. Arthritis Res Ther. 2010;12(3):R122. https://doi.org/10.1186/ar3060.

13. Van der Kooij SM, De Vries-Bouwstra JK, Goekoop-Ruiterman YPM, et al. Limited efficacy of conventional DMARDs after initial methotrexate failure in patients with recent onset rheumatoid arthritis treated according to the disease activity score. Ann Rheum Dis. 2007;66(10):1356-62. https://doi.org/10.1136/ ard.2006.066662.

14. Malaviya AN. Landmark papers on the discovery of methotrexate for the treatment of rheumatoid arthritis and other systemic inflammatory rheumatic diseases: a fascinating story. International Journal of Rheumatic Diseases. 2016;19:844-51. https://doi.org/10.1111/1756-185X.12862.

15. Ally MM, Meyer PW, Anderson R. Early rheumatoid arthritis: focus on RA in the developing world. South African Fam Pract. 2016;58(4):164-6. https://doi.org/ 10.1080/20786190.2016.1177988.

16. Bester FCJ, Bosch FJ, Van Rensburg BJJ. The specialist physician's approach to rheumatoid arthritis in South Africa. Korean J Intern Med. 2016;31(2):219-36. https://doi.org/10.3904/kjim.2015.134.

17. Smolen JS, Landewe R, Breedveld FC, et al. EULAR recommendations for the management of rheumatoid arthritis with synthetic and biological diseasemodifying antirheumatic drugs: 2013 update. Ann Rheum Dis. 2014;73(3):492509. https://doi.org/10.1136\%2Fannrheumdis-2013-204573.

18. Maetzel A, Wong A, Strand $V$, et al. Meta-analysis of treatment termination rates among rheumatoid arthritis patients receiving disease-modifying anti-rheumatic drugs. Rheumatology. 2000;39(9)975-81. https://doi.org/10.1093/ rheumatology/39.9.975.

19. Donahue KE, Gartlehner G, Jonas DE, et al. Systematic review: comparative effectiveness and harms of disease-modifying medications for rheumatoid arthritis. Annals of Internal Medicine. 2008;178:124-34. https://doi. org/10.7326/0003-4819-148-2-200801150-00192.

20. Plosker GL, Croom KF. Sulfasalazine: A review of its use in the management of rheumatoid arthritis. Drugs. 2005;65:1825-49. https://doi. org/10.2165/00003495-200565130-00008.

21. Rainsford KD, Parke AL, Clifford-Rashotte M, Kean WF. Therapy and pharmacological properties of hydroxychloroquine and chloroquine in treatment of systemic lupus erythematosus, rheumatoid arthritis and related diseases. Inflammopharmacology. 2015;23:231-69. https://doi.org/10.1007/ s10787-015-0239-y.

22. Peters MJL, Symmons DPM, McCarey D, et al. EULAR evidence-based recommendations for cardiovascular risk management in patients with rheumatoid arthritis and other forms of inflammatory arthritis. Ann Rheum Dis. 2010;69(2):325-31. https://doi.org/10.1136/ard.2009.113696.

23. Varga Z, Sabzwari S rafay ali, Vargova V. Cardiovascular risk of nonsteroidal anti-inflammatory drugs: an under-recognized public health issue. Cureus. 2017;9(4):e1144. https://doi.org/10.7759/cureus.1144.

24. Hodkinson B, Musenge $E$, Ally M, et al. Response to traditional disease-modifying anti-rheumatic drugs in indigent South Africans with early rheumatoid arthritis. Clin Rheumatol. 2012;31(4):613-9. https://doi.org/10.1007/s10067-011-1900-5.

25. Singh JA, Saag KG, Bridges SL, et al. 2015 American College of Rheumatology Guideline for the Treatment of Rheumatoid Arthritis. Arthritis Rheumatol. 2016;68(1):1-26. https://doi.org/10.1002/art.39480.

26. Tarr G, Hodkinson B, Reuter H. Superheroes in autoimmune warfare: Biologic therapies in current SA practice. South African Med J. 2014;104(11):787-91. https://doi.org/10.7196/SAMJ.8947.

27. Alfonso-Cristancho R, Armstrong N, Arjunji R, et al. Comparative effectiveness of biologics for the management of rheumatoid arthritis: systematic review and network meta-analysis. Clin Rheumatol. 2017;36(1):25-34. https://doi. org/10.1007/s10067-016-3435-2.

28. Smolen JS, Landewe R, Breedveld FC, Buch M, Burmester $G$, Dougados $M$, et al. EULAR recommendations for the management of rheumatoid arthritis with synthetic and biological disease-modifying antirheumatic drugs: 2013 update. Ann Rheum Dis. 2014;73(3):492-509. https://doi.org/10.1136/ annrheumdis-2013-204573.

29. Van Duuren E. Use of biological agents in rheumatic disease. C Your SA J CPD. 2011;33429(8):334-6.

30. Louw I. Biological therapies in rheumatic disease. C Your SA J CPD. 2005;23(10):518-9.

31. Ramiro S, Gaujoux-Viala C, Nam JL, et al. Safety of synthetic and biological DMARDs: a systematic literature review informing the 2013 update of the EULAR recommendations for management of rheumatoid arthritis. Ann Rheum Dis. 2014;73(3):529-35. https://doi.org/10.1136/annrheumdis-2013-204575. 